\title{
Obstetric/Paediatric Interaction in Brain Damage Litigation: Learning from the Courts
}

\section{George Gregory Buttigieg*}

Department of Obstetrics and Gynaecology, Mater Dei Hospital, Malta

\begin{abstract}
The multifaceted relationship between obstetrician and paediatrician is looked at within the framework of Court medico-legal action concerning neonatal brain damage, as exemplified by cerebral palsy. Antenatal and intra-partum aspects are analysed, and the potential for a preventive role in inter-disciplinary antenatal consultations advocated. It is suggested that, those instances of HIE with possible antenatal identifiable risk factors, could benefit from a combined obstetrician-paediatrician as part of antenatal management. The crucial importance of the paediatric role in optimal resuscitation, and later management is also stressed as benefitting both the neonate and limiting possible future obstetric liability. The paediatrician's roles in establishing HIE along the ACOG-AAP 2003/2014 Classification is also evaluated. Borrowing extensively from UK Court archives, frequent reference is also made to specific Court case examples, oriented around obstetric/paediatric liability based on alleged, and at times, upheld medical malpractice.
\end{abstract}

\section{Introduction}

The obstetrician, paediatrician, anaesthetist and midwife, form a core care group, which has revolutionised the management of obstetrics. All are indispensable, even if, it is the obstetrician who plays the central role. And naturally, it is most often the obstetrician, though not invariably so, who will face liability claims in situations involving neonatal brain damage, such as hypoxic ischaemic encephalopathy (HIE) and cerebral palsy. We speak of no small amounts of money being awarded in cases of proven liability, in cases of brain damage, but rather, of average Court awards often exceeding \$3,000,000. Although, paediatricians, generally speaking, were originally, out of the litigation limelight, they have faced Court action with increasing frequency, especially in neonatology [1]. Such action is still, nowhere as frequent as that faced by obstetricians. This article looks at some aspects of the inter-action between the two specialities brought about, directly or indirectly, by the litigation aspect of brain damage, the commonest manifestation of which being cerebral palsy.

The plague of unwarranted Court litigation is rightly considered by one and all, as harmful, not only to most of the parties involved, but also to national health systems and healthcare schemes. It is beneficial to the less than 1 in 10 [2] plaintiffs who win their cerebral palsy Court and it is certainly beneficial to those "stakeholders" riding selfishly, piggy-back on the pain of others [3]. Yet, medico-legal litigation can also teach lessons to improve future practice [4]. It is interesting to note that medico-legal inter-actions between paediatrician and obstetrician change the normal pecking order between the two. When Court beckons, the paediatrician's output, consciously or unconsciously, may have much influence on the obstetrician's fate. In fact, we can go further than this and state, that, given a chance by the obstetrician, the well intentioned paediatrician, may even positively influence the obstetrician's lot, pre-emptively, in the antenatal period.

\section{Pediatric Influence at Antenatal Level}

Very often, the paediatrician enters the "obstetrician's stage", when summoned by the birth cue. Till then, the obstetrician has centre stage. Unfortunately, in a world of medical specialists, sub-specialists and super sub-specialists, there is little room left for primadonnas. Lessons should be learnt from the unfortunate outcomes of medicolegal litigation, which teaches that often, he who stars alone in a clinical setting also stars alone in Court. In brain damage litigation, one aspect of improving matters at Court should have commenced much earlier than the time of birth itself. Good antenatal management demands that in those cases, where the obstetrician, foresees the least potential of a birth oriented cerebral damage setting, he should consult with his chosen paediatrician. Such examples may include severe fetal growth restriction, chorio-amnionitis, oligohymranios, relebat antgenatal medications, niggling premature labour...Such management sharing is not common but may pay dividends. Ensuring the right choice of anti-microbial therapy in chorio-amnionitis, deciding the optimal date for an elective premature delivery, manoeuvring the most experienced paediatric on call duty, while shifting less "equal ones....are factors not to be decried. The very suitability of one's obstetric unit may need to be changed on paediatric advice e.g. the referral of cases of triplets to a tertiary centre. In French $v$ Thames Valley Strategic Health Authority, initially, a point arose as to whether the defendant was negligent in not transferring the plaintiff to the Oxford Special PET Centre [5]. Shifting aside ego, for safety and ideal may not come easy, but it is cheaper than a possible ruinous Court trial which could have been avoided.

If such a logical and wise consultation, does take place, it speaks much in favour of the obstetrician's attitude to genuine care of his patient. As such, it should be fully and formally annotated in the patient's clinical file, along with the aim of the consultation, the conclusions drawn and how they were to be affected. If ever matters reach Court, facts like these argue for the planning of optimal care. The conclusions of such consultations should also be shared with the patient and her husband. Indeed, in worrying cases, it is reassuring for the

*Corresponding author: George Gregory Buttigieg, Senior Consultant, Department of Obstetrics and Gynaecology, Mater Dei Hospital, Malta, Tel: +356 2340 1102; E-mail: george.g.buttigieg@um.edu.mt

Received September 23, 2016; Accepted October 25, 2016; Published October 31,2016

Citation: Buttigieg GG (2016) Obstetric/Paediatric Interaction in Brain Damage Litigation: Learning from the Courts. J Pediatr Neurol Med 1: 115. doi:10.4172/2472100X.1000115

Copyright: @ 2016 Buttigieg GG. This is an open-access article distributed under the terms of the Creative Commons Attribution License, which permits unrestricted use, distribution, and reproduction in any medium, provided the original author and source are credited. 
parents to be spoken to, well ahead of delivery day, by both obstetrician and paediatrician.

Not only does this not lower the obstetrician in the couple's eyes, the opposite is true as it inculcates a deep sense of care and preparedness. Good communication, the basis of good practice, will help instil confidence and foster a humane, empathic and successful relationship [3]. It also diminishes the argument of he "did not tell me" as found in Loraine v Wirral University Teaching Hospital NHS.

\section{Foundation Trust}

Of course, active withholding of information, even if done out of fear of generating anxiety, is, by itself, serious ground for litigation as we find in Nadine Montgomery v Lanarkshire Health Board [6]. Physicians, who fail to provide the required information, risk liability, even if the physician is not negligent in performing the procedure. With the paediatrician by his side antenatally, all paediatric queries may be aired freely, even if facts will eventually show this to have been a mercifully unnecessary exercise.

Such combined patient discussions should be ideally held, well before the moment of delivery, be it a planned vaginal or an elective caesarean section. Making the patient's acquaintance in the delivery room or in the operating theatre, where the patient's attention may be easily dulled by the tension, fear and distractions [7]. Information garnered just before shock induced stress, often results in amnesia [8]. Such a session need not generate undue anxiety, but take the form of how the child will be managed in the different circumstances, which might ensue. Such 'pre-birth' discussions with the patient and her partner/ husband will also help diminish one of the commonest complaints of patients that of feeling ignored or even mistreated [9].

Planning optimal care may mean that both senior obstetrician and paediatrician are the "men on the spot" on the day of delivery. This again may argue favourably in any ensuing litigation. Medico-legally, the obstetrician answers for his intra-partum care, but he may also have to answer for the final outcome of the neonate's state, when suboptimal care has been delivered by the neonatal paediatrician. Such a challenge to obstetric liability may come, 10, 15, 20 years later. It may be extremely difficult, to separate obstetric intra-partum care, from possible sub-optimal care and its long term effect. Ensuring the best from all angles, in cases where this is possible, is ideal, firstly for the neonate himself, and secondly, for any possible litigation.

\section{Intra-Partum Inter-Action}

As a rule, in most units, the paediatrician is called at birth, even, when all is as it should be. In elective cases, procedures, will not or should not, be commenced, unless otherwise dictated by circumstances, until the paediatrician is actually present. This applies to all caesarean sections, instrumental deliveries and all deliveries involving high risk situations, such as deliveries of diabetic mothers, multiple pregnancies, VBAC and breech deliveries. In such cases, good paediatric care does not cease at birth, for it is by no means rare, that infants born in these circumstances, may appear initially stable at birth, but decompensate within $12-48 \mathrm{~h}$. In Smithers $v$ Taunton and Somerset NHS Trust [10] we find:

...Essentially reliance is placed on the Defendants' own protocol, which required (a) an anaesthetist, a paediatrician and SCBU to be notified when the patient was in established labour...Reliance is also placed on various extracts in the medical literature bundle, which draw attention to the high level of assistance required in a breech labour. The American authors of Williams Obstetrics state, for example:
"Timing of delivery...It is essential that the delivery team include (1) An obstetrician skilled in the art of breech extraction, (2) An associate to assist with the delivery, (3) an anesthesiologist who can assure adequate anesthesia when needed and (4) an individual trained to resuscitate the infant including tracheal intubation."

Sometimes, it is the paediatrician who faces liability in faces of peripartum hypoxia and in Dunne (an infant) (suing by his mother and next friend Fiona Murphy) $v$ Coombe Women and another [11], we find an unusual scenario, where HIE resulted from peripartum but post-natal hypoxia. In this case, the first intubation failed as did the second, and delivery of the necessary oxygen came too late to avoid cerebral damage. The paediatric defendant tried to shift the cause to an intra-uterine cause, i.e., involving obstetric liability. This humanly understandable, desperate defence, raised eyebrows:

As to the line of examination pursued by the Defendant regarding causation, Prof Flemming stated that he had never seen a baby silently injured in utero without signs or symptoms and he could not imagine a mechanism whereby a baby could sustain an injury caused by a 10 to 25 min period of hypoxia and then continue to develop normally in utero thereafter. He expressed surprise that the Defendant could put forward a case that somehow Eoin could have had a major hypoxic ischaemic event which could then have resolved spontaneously without a trace of any abnormality appearing on the CTG prior to birth.

Then, there are situations, where the origin of HIE may appear confusing at first glance, and jurisprudential evaluation requires greater than average consideration. One such case can be found in Quaye $v$ Guy's and St Thomas' NHS Trust [12]. This case was misdirecting by CTG abnormalities and the fact that the child was born rather "flat" and covered in meconium. Superficially, obstetrician malpractice seemed responsible or else contributory to the eventual course of development of HIE associated with cerebral palsy. This was certainly the stand taken by the defendant paediatrician, who, having accepted his own negligence, claimed obstetric contribution to the final state of the infant's HIE. However, close scrutiny of the facts, demolished this argument for the CTG disturbance involved "a sudden deceleration... probably due to a transient occlusion of the umbilical cord... the recovery was rapid and the foetus was coping well". Furthermore, the umbilical arterial $\mathrm{pH}$ was 7.24. And the fact that the deterioration from oxygen deprivation occurred in the first few days of post-natal life clinched the situation. In the Judge's summing up we find:

"It is virtually certain in my opinion, that Jared's disabilities are attributable to hypoxic/ischaemic brain injury acquired following birth during his severe neonatal illness. I think it most unlikely that he sustained any element of his brain injury prior to birth although I think that there was a degree of intrapartum asphyxia which was responsible for his passing and inhaling meconium. The [most cogent] evidence in support of the proposition that brain hypoxia/ischaemia occur-ring postnatally is much more likely to account for Jared's brain injury than if it occurred prenatally..."

These sad examples of negative obstetrician/paediatric interactions at Court level are, thankfully, by no means common. Though, on the human level, they are understandable, it is crucial that the correct picture emerges, and that responsibility be laid at the right door.

\section{Re-Fashioning the Classical Neonatologist's Role}

In most laymen's minds, the neonatologist resuscitates the neonate, which, in fact is the case. His role, however, is much broader, deeper and is multifaceted. Here, we are concerned with some of the aspects 
of his work as it impinges on the obstetrician's in the medico-legal aspect of brain damage. The statement that the obstetrician delivers the baby from the mother and the paediatrician delivers the baby from the obstetrician, is correct, but hides oceans of implications. In labour, the neonatologist's work ranges from semi-token when all is well to life saving or damage limitation in cases of brain damage.

At times, unfortunately, things may go wrong from the neonatologist's aspect. Such situations may open him to liability and it is well to remember the top ten allegations [13] of professional liability against practitioners of perinatal medicine:

Inadequate airway/intubation (21\%)

Failure to recognize air leak (18\%)

Delayed transfer to Level III facility (14\%)

Inadequate treatment of seizures (11\%)

Delayed attendance at delivery (10\%)

Cardiac tamponade (malposition central line) (6\%)

Failure to perform eye exam (6\%)

Medication error (6\%)

Midgut volvulus (5\%)

Hyperbilirubinemia (kernicterus) (3\%)

It is to no nobody's comfort, that the paediatrician, is also, although to a lesser degree than the obstetrician, in the Court's telescopic cross-lines. In Wilsher $v$ Essex Area Health Authority [14] a paediatrician faced liability charges (not upheld by the Court) in a case involving a premature birth, unaccompanied by any evidence of brain damage. However, the child developed blindness through Retrolental Fibroplasia in a situation where the cause was alleged due to the fact that a catheter had been twice inserted wrongly and excess oxygen delivered on both occasions.

In Smith (by her mother and litigation friend Smith) $v$ East and North Hertfordshire Hospitals NHS Trust [15], a six day old child at the Lister Hospital Stevenage, was accidentally given a grossly excessive infusion of dextrose, resulting in convulsions and permanent brain damage. Although paediatric liability was proven, one wonders about the possibility of alleged obstetric birth liability, had the mistake occurred when the child was $6 \mathrm{~h}$ and not six days old. One may argue that eventually truth will out, but the Court is littered with cases with even less evidence, where truth surfaced after long and expensive trials. Especially so in a climate linking any form of brain damage to any CTG monitoring 'abnormalities', until proved otherwise. While, meritorious allegations against practitioners in new-born care are frequently preventable events, it is also correct to state that substandard neonatal resuscitation in the delivery room can also propagate non-meritorious allegations against obstetricians [13].

In the vastly commoner situations of HIE associated with intrapartum hypoxia and hence lying within the obstetricians are of liability, one must remember that such litigation may commence decades later, when the neonate has reached late teens or even young adulthood. Hence the critical importance of clear, precise, dated and timed (to the minute) recording of all actions - obstetric and paediatric - in the clinical notes. Legible handwriting may be a silly point to stress, but numerous Court cases have been flawed because of this [3]. In the context of proving the presence or absence of HIE, the paediatrician is usually the key person who supplies the individual units, which collated may constitute the four core criteria, advised by the along the 20032014 ACOG-AAP Classification [16,17], namely:

1. Apgar Score of Less than 5 at $5 \mathrm{~min}$ and $10 \mathrm{~min}$

2. Fetal umbilical artery $\mathrm{pH}$ less than 7.0 or base deficit greater than or equal to $12 \mathrm{mmol} / \mathrm{L}$, or both,

3. Neuroimaging Evidence of Acute Brain Injury Seen on Brain Magnetic Resonance Imaging or Magnetic Resonance Spectroscopy Consistent With Hypoxia-Ischemia

4. Presence of Multisystem Organ Failure Consistent With Hypoxic-Ischemic Encephalopathy

\section{The Cerebral Palsy Story}

The sad birth of an infant with brain damage such as cerebral palsy may conclude the first chapter of the obstetrician's clinical involvement. The second chapter may begin decades later, and this time, not in the labour ward, but the arena of Court.

The paediatrician shares both these chapters, for in the second one, he must appear in Court as witness to the facts and to explain his clinical role, albeit. Not usually, facing liability. However, after birth, he begins his own, never ending clinical involvement as the infant grows and develops while facing monumental challenges along with his often devastated parents. For it is often the paediatrician who, after the initial diagnosis and management, co-ordinates the team involved in the child's care. It is the paediatrician who normally leads the multi-disciplinary team approach to establish diagnosis, assess the situation periodically and co-ordinate the optimal approach and timing of the various clinical inputs. The evaluation of such a child is an on-going process as the child grows from infancy to adolescence [18]. A multitude of specialists need to be involved, each playing crucial roles of treatment, support and hopefully optimal management of a catastrophe, which often draws in the whole family and its circumstances. Neurologists, neuro-radiologists, psychiatrists, educators, orthopaedic surgeons, occupational therapists, ophthalmologists, audiologists and social workers, often all have roles to play, with some more than others at various times. Often, it is the paediatrician, who co-relates issues reports and guides, at least in the first decade or so. Reports from all specialists will also need to be updated, if obstetric liability is decreed by the Court, which must next decide on quantum. Such calculations will not only comprise the status quo but also need to work out future projections regarding financial evaluations which include the domestic arrangements and at times even the needs for new housing.

The unfortunate occurrence of a brain damaged neonate and its liability, provides an extensive challenge to paediatric-obstetrician inter-action. This inter-action has many facets - preventative, curative, supportive and medico- legal. Ideally, there should be an increase in pre-emptive antenatal consultations. Once, disaster has struck, objective retrospective analysis of the situation should be resorted to, both as a future eye opener and also, if the need arises, for use future litigation. The paediatrician, should also, hopefully in the not too distant future, be able to offer more help in HIE management, where prevention and more effective treatments are still needed [19].

\section{References}

1. Hayes Brown R (1976) The pediatrician and malpractice. Pediatrics 57: 392 401.

2. Freeman JM, Freeman AD (2003) Risk management foundation. No-fault neurological compensation: Perhaps it's time has come, again. Harvard Med Inst Forum, pp: 5-6. 
Citation: Buttigieg GG (2016) Obstetric/Paediatric Interaction in Brain Damage Litigation: Learning from the Courts. J Pediatr Neurol Med 1: 115. doi:10.4172/2472-100X.1000115

3. Buttigieg GG (2016) Minimizing obstetric medico-legal litigation. International Journal of Gynecological and Obstetrical Research 4: 22-30.

4. IBID.

5. French $v$ thames valley strategic health authority (2005) EWHC 459 (QB).

6. Nadine Montgomery v Lanarkshire Health Board (2010) CSOH 104.

7. Buttigieg GG, Buttigieg G (2014) Medico-Legal Litigation: The clinical contractual nature of the Obstetric Anaesthetist -Patient relationship. Malta Medical Journal 26: 44-48.

8. Park CR, Zoladz PR, Conrad CD, Fleshner M, Diamond DM (2008) Acute predator stress impairs the consolidation and retrieval of hippocampusdependent memory in male and female rats. Learning and Memory 15: 271280 .

9. Ross BK (2003) ASA closed claims in obstetrics: lessons learned. Anesthesio Clin North America 21: 183-197.

10. Smithers v Taunton and Somerset NHS Trust (2004) EWHC 1179 (QB).

11. Dunne (an infant) (suing by his mother and next friend Fiona Murphy) $v$ Coombe Women and another (2013) IEHC 58.
12. Quaye v Guy's and St Thomas' NHS Trust (2001) Lexis Citation 1169. Queen's Bench Division.

13. Muraskas J, Ellsworth L, Culp E, Garbe G, Morrison J (2016) Risk Management in Obstetrics and Neonatal-Perinatal Medicine.

14. Wilsher v Essex Area Health Authority (1988) 1 AC 1074.

15. Smith (by her mother and litigation friend Smith) v East and North Hertfordshire Hospitals NHS Trust (2008) EWHC 2234 (QB).

16. The American College of Obstetricians and Gynecologist's Task Force on Neonatal Encephalopathy and Cerebral Palsy, the American College of Obstetricians and Gynecologist's, the American Academy of Pediatrics (2003) Neonatal encephalopathy and cerebral palsy: Defining the pathogenesis and pathophysiology. The American College of Obstetricians and Gynecologist's, Washington, DC.

17. http://www.acog.org/About-ACOG/News-Room/News-Releases

18. Aneja S (2004) Evaluation of a child with cerebral palsy. The Indian Journal of Pediatrics 71: 627-634.

19. Colditz P (2014) Commentary: Neonatal hypoxic-ischaemic encephalopathy: What lies ahead? Developmental medicine \& Child Neurology 56: 1033 